\title{
Climate Change and the Problem of Representation
}

\section{Emily Potter}

How do we know climate change? How do we encounter its reality? This question brings to mind a history of scepticism and denial - those who ask 'where is the evidence?' against scientific efforts to model and map out predicted temperature rises. Yet the word prediction is telling here: how can you know something that is still unfolding? In order to respond to the manifesting consequences of environmental change, there is an imperative to capture and convey change in the midst of process. Somewhere between scepticism and prediction is the problem of representation - a concern that unites scientists and artists in the desire to say something of truth about the world. Signs of change obsess us and we look to science for orientation through these. Poetic representation is valued as a tool of communication and inspiration - to educate, warn and motivate responses. Yet as the consequences of climate change continue to manifest, representation sits ambiguously in a context of these materially-grounded concerns. This paper offers a rethinking of the role of representation in environmental discourse. It suggests that rather than representation's inability to access the real, the more pressing issue is the relationship between humans and the non-human environment that modes of representation assert. It is ultimately our ontological and epistemological traditions, and the work of representation within these, that determine our distance from or proximity to the elements of a transforming ecology.

\section{Representing climate change and calculating environments}

Appeals to the authority of scientific representation are common in the public discourse of climate change: data - a translation of scientific findings - conveys environmental conditions, and is harnessed in defence against climate change denial. 'Good science', defined by Barry Brook as 'evidence and ideas that are repeatedly supported by observations, experiments and models', is sought to defeat the 'charlatans' and to guide our appropriate responses to the issue (Brook 30). Novelist Ian McEwan similarly articulates the value of data relating to climate change in the public realm, arguing that '[w]e need accurate representations of the state of the earth. The environmental movement has been let down by dire predictions, "scientifically" based, which over the past two or three decades have proved spectacularly wrong...We need not only reliable data, but their expression in the rigorous use of statistics' (McEwan). McEwan also points to the associated role of discourse, text and 'talk' with scientific information, not 
as a secondary thing, but as a process in its own right: 'Can we avoid what is coming at us, or is there nothing much coming at all? ... Is this the beginning, or the end? We need to talk' (McEwan). In this account, what is first conveyed in scientific data must also be narrativised for public debate and understanding. Other commentators describe the relation between scientific and discursive or artistic representation more decidedly. Bill McKibben, for example, suggests the value of the latter is to overcome the instrumentality of science in order to work on affective rather than rational levels. 'We can register what is happening with satellites and scientific instruments', he writes, 'but can we register it in our imaginations, the most sensitive of all our devices?' (McKibben). Calling on creative artists to engage with the topic, McKibben wonders 'what emotions should the playwright play with - fear? Guilt? Sure, but not only those... There also needs to be hope as well... [These] don't have to be romantic visions, though a little romance wouldn't hurt' (McKibben).

In such accounts, these different modes of representation - the positivist and the poetic - fulfil different functions, but connect on a significant level. Both are understood to offer access to, and to speak on behalf of, a singular nature or environment. Representation becomes a means of reconciling 'inner' and 'outer' worlds of experience (McKee 534), and in this context facilitates a political ambition, enabling us to act on nature's behalf in the face of human-authored change. The inheritance of western thought post-Descartes is, of course, evident here, with its conceptual division between human and non-human, culture and nature. Within these binaries, power is allocated unevenly, with the capacity to do, to have creative impact, and to author, invested in the human. Where the non-human environment 'acts' — for instance, in the case of a 'natural disaster' — it is interpreted with the human at the centre of concern: what does the occurrence mean for humans? How it can be read or interpreted in order to understand ourselves better? This tradition does not preclude human and non-human entanglements, but it interprets these as reflecting human power and indicative of human culture. Two examples illustrate this way of thinking; while not emblematic in any totalising way, they do indicate a tendency to see the work of representation as mediating an implicitly passive nature through the frame of culture.

First, certain conventions in ecocritical work - a field that traditionally concerns itself with the textual production and mediation of environmental discourse and human/non-human relations - position the question of how humans define and represent the Earth as central to their analysis. What humans do to the non-human world, and the meanings of these actions, is the focus of its critique and revision, while poetic representation is positioned as a window to the material real. In this kind of eco-critical practice, there is an implicit distance implied between the reader and the world, and it is on the 'readerly' side that meaning is made. Greg Garrard's Ecocriticism demonstrates this point. Garrard claims that 
in its 'widest definition... the subject of ecocriticism is the study of the relationship of the human and the non-human, throughout human cultural history and entailing critical analysis of the term "human" itself" (5) [emphasis mine]. While human/non-human relations may be the concern here, it is the work of culture to imagine and interpret nature that is seen to offer us insight. Nature - or the non-human - is not an active participant in the process. 'Environmental problems', Garrard continues, 'are the outcome of an interaction between ecological knowledge of nature and its cultural inflection' (14). This view suggests that environmental conditions ultimately hold a mirror to culture, and are defined by a transaction between different understandings of the world.

Second, evident parallels exist between these textual traditions of ecocriticism and broader discourses - in a range of professional, theoretical and creative fields - of 'environmental communication'. These frequently employ a bifurcated view of the non-human world as something that exists outside us: it is the human who acts (informed by communication), and the environment that is acted upon. Appeals to 'care for the environment' tend to reveal this logic, as a recent water saving campaign in Victoria shows: 'Climate change and the ongoing dry conditions mean the way Victorians value and use water must change forever. We are in a serious situation and every person, every day, can make a huge difference by adopting simple water saving solutions' ('Our Water, Our Future'). Such renderings of communication as a transformative conduit between human activities, especially in environmental policy rhetoric, are echoed in a range of discursive and poetic sites, from environmental lifestyle literature to environmental art (Potter). I want to explore this now briefly through the 'ecological footprint', a signature concept, tool and new measure of citizenship that has risen to prominence in the popular environmental imagination. The footprint illustrates well the convergence of the positivist and the poetic modes of representation in the service of a collective political project - or as Latour says, of 'making things public' (Latour, 'Dingpolitik'). It also suggests all that is absent, all that falls away, from a calculative view of the world.

The ecological footprint is presented as a measure of human environmental impact, based upon amounts of energy consumption, land and water use and waste production. The concept began as a collective one, developed to assess through spatial representation what Andrew Light calls 'the full ecological burden of cities on the environment' (44). In this tradition, maps are generated using GIS (Geographic Information System) data and are coupled with statistics of consumption to assess the ecological footprints of cities against their actual physical boundaries. In most cases in the global north, the footprint far exceeds these boundaries. The figures that are generated through this process - for instance, that the ecological footprint of London is larger than the size of Britain (Light 46)-represent the problem and call for a solution. They convey the apparent, unsustainable reality of our culture. 
A recent plethora of internet-based calculation tools, and even multiple response Q\&A tests, have translated the footprint to the local level, where it becomes a sign for a household, business or individual's environmental relation. Carbon calculators offer such an interpretative function. As The Rough Guide to Climate Change explains, 'just as new dieters keep a food diary, an excellent way to start reducing (our) carbon emissions is by using a carbon calculator... Simple online tools allow you to calculate how much carbon each activity in your life generates and how your total compares to those of the people around you and elsewhere in the world' (Henson 313). The idea is that not only will the ecological or carbon footprint translate ecological processes into directed data; ultimately, it will translate into action. Through the reading of this indexical sign, the discourse suggests, individuals and publics alike will be inspired to alter their environmental practices.

The ecological footprint has become the emblem of a new site of political representation - ecological citizenship - within which the environment is understood as a 'public good to defend' (Sáiz 164), and the concept of 'rights' is expanded to incorporate the non-human world. For humans, the traditional focus of citizenry rights shifts to the responsibility, or obligation, to service these non-human rights, as well as those of future human generations. The appeal to 'tread lightly' upon the earth has become a slogan for this revised notion of citizenship, eschewing human dominance and moral disconnection from the imprint of our actions.

The problem with this rendering of human/environment relations is that the footprint, as a representation of environmental change, is singular and un-dynamic. It instrumentalises relations between the assemblage of people, places, environments and emissions that it encompasses, excluding less calculable manifestations of impact and effect. Moreover, it pacifies the environment, operating on the assumption of a non-discursive relationship between human action and environmental imprint. Thus while the non-human world is attributed rights, it is still accorded no agency. Indeed, in the image of the weighty foot upon the earth, the ground is configured as de-creative - its only response is to come undone.

Paul Carter writes in The Lie of the Land about the fetish of the footprint in Daniel Defoe's Robinson Crusoe - how the single footprint that Crusoe finds in the island sands throws his world into chaos. Signifying presence where he previously perceived absence, the footprint generates a series of ontological anxieties: Crusoe is not alone as he had thought. But like the ecological footprint, the signifying circuit of the impression in the sand means that it will always link back to him. As Carter contends, 'Crusoe holds no dialogue with his surroundings, only with himself'; 'the environment only signifies in so far as it supplies him with a tabula rasa whereon he can inscribe a hemisphere with himself at its centre' (10). What 
Carter intuits from this sequence is the dangerous capacity of signs - as something standing in for something else' (11) - to circumscribe what counts as knowledge and to internalise a single reality. The most disturbing thing about Crusoe's fixation with the footprint is that he does not ask, 'where is the other one?' It is just the single footprint that concerns him. Because of this, he never opens himself up to an ecology of relations that two footprints or more, diffusing into mobile patterns of presence, would suggest. His interpretive frame shuts out contingency and uncertainty, and the supernatural power of the sign is affirmed.

What is consequently lost to Crusoe is the capacity to see himself as part of a continually composing place. The ground beneath his own feet is not firm, but vibrates in a network of human and non-human traces. A single footprint in the sand can suggest a deceptive present that interpretation seeks to master; but it can also reference the beginning of a dynamic and material encounter between body and earth. It means that the single footprint-and the truth that it captures - manifests through the 'process of artful deletion' (Law 88). In this refusal to see the foot as singular, absence and presence become ambiguous states. A footstep in the world thus calls up an environment of traces, a 'hidden geography' of gatherings and assemblages (Latour, 'Dingpolitik' 15).

This suggests that there is no certain place from which we can survey the world and uncover its truth. It also suggests that poetics are essentially relational- they indicate the proximity or distance between things by operating in an ecological fashion, as always partially realising a picture of reality because they constantly allude to their connected context, beyond - but related to - themselves. Methods of representation are thus not impartial tools. To recognise this means to embrace quite a different way of configuring knowledge that undoes hierarchies of expertise, authorship and presence.

\section{Natureculture and more-than-representational thinking}

Natureculture theory offers a challenge to the centrality of humanness for realising reality in much representational thinking. This theoretical reorientation of the terms in which human/non-human relations are considered makes a shift from considering the environment as a determinate thing that we represent, to approaching it as 'a figure that mediates a network of sociopolitical, economic, and natural forces' (McKee 541). Natureculture theory thus decentres the human subject, not so as to deny it actancy or affect-as the fantasies of some environmentalism would have it: the notion of 'pristine wilderness', for example - but in order to recognise co-constitution, and to flatten out hierarchies of impact and effect. Its conceptual ambition is to unsettle the ecological arrangement that would situate the human as the nodal hub of activity and meaning-making, and instead, to understand the human as part of an assemblage of what is reality. A natureculture is just this: an assemblage of 'people, things, 
laws, politics, techniques and ethical strategies' (Muecke 132), which means that no one participant in this ever-moving network has an omnipotent purchase on the truth of the matter.

While natureculture theory is not new in pointing out the entwined destinies of humans and non-humans (for ecocriticism does this too), its innovation is to question the fundamental categories through which we address human/non-human relations and to see these relations as always co-constitutive. 'Nature' and 'culture' as pre-given categories are thus questioned in this theoretical frame, not discrete entities involved in relations of power, but rather referencing an assemblage of non-human and human entities and forces. Bruno Latour, an initiating figure of natureculture theory, affirms this: 'contra appearances, nature is always entangled with culture and society' (in Law 120). Here on the level of the 'thing' or the 'object', a gathering of different phenomena and energy produces its reality in temporal ways - temporal because the thing's constitution remains open-ended. This thinking confronts the terms in which environmental debate frequently takes place, and the assumptions of human activity and non-human passivity upon which these draw.

Recently, an increasing frustration in the academy with the limits, exclusions and sometimes the conceit of representational thinking has occasioned the rise of what have been termed 'non-representational' and 'more-than-representational' thinking, particularly emerging from the humanities and social sciences disciplines whose work continually comes up against the recalcitrance of matter - for example, cultural geography, the philosophy of science, and creative arts research. These feed into natureculture theory. They emphasise more-than-textual ways of knowing the world; knowledge emergent from embodied process and material practices - or to put it another way, the dance of feet is the site of interest, rather than the single footprint. This confronts the transcendent authority of calculation.

John Law argues for an alternative view of how we know material reality based upon this recognition of what calculation can never capture. He writes, 'the world is not to be understood in general by adopting a methodological version of auditing... [It is] not ... a structure, something we can map with our social science charts. We might think of it, instead, as a maelstrom or a tide-rip. Imagine that it is filled with currents, eddies, flows ... and moments of lull and calm... Certainly there are moments when a chart is useful, when it works... But a great deal of the time this is close to impossible' (6). Latour's concept of a gathering reality models the different and mobile geographies of knowledge that resist such auditing. This view refuses the translation of fact into reality. Before the question 'what do we know?', Latour asks 'how does what we know come to be?' 
Facts, in his view, provide a paltry representation of reality. Rather, facts gather with a range of other material and immaterial energies, entities and happenings to produce what Latour terms a 'matter of concern'. A range of matters of concern collide in temporal ways to constitute what he then defines as 'the state of affairs' (232). The matter of concern-climate change, for example - is the focus of study, but unlike a matter of fact, the matter of concern refutes any claim we would make to speak its truth entirely. It is emergent from an assemblage of expertise, feelings, visions, interests, histories and materials, and we can never know a matter of concern in a single way. Its reality is continually manifested as these phenomena gather together.

This challenge to the ascendancy of a singular reality is considered by Latour to be a way of renewing empiricism rather than leaving it behind - an empiricism that is methodologically expanded and locally situated within an ever-unfolding network of relations. John Law's account of the 'messy' textures of reality (2), in the context of representational research traditions, similarly situates knowledge in a provisional field of daily experiences, encounters and methodological interventions. He argues in reference to our attempts to make sense of the world, 'events and processes are not simply complex in the sense that they are difficult to grasp... Rather, they are also complex because they necessarily exceed our capacity to know them' (6). That is, no matter how much detail and technical expertise goes into a representation like the ecological footprint, it will never capture the mobile energy, the lived, ongoing relations with the world, of the active ecological citizen. But how exactly can we derive a representative politics from this view of assembling reality? The response that I want to offer to this question also suggests a way of rethinking the work of representation - not as mediating the world and inspiring behaviours accordingly, but as actively contributing to the production of publicness and new narratives of responsibility and relation that can emerge in this space.

\section{Representation in the public realm}

Rather than a pre-existing identity that representation affirms, ecological citizenship is more usefully understood as emerging in temporally contingent and discursively mobilised moments of collective response. Both material and ephemeral, it arises from the kind of gathering formation that Latour describes, where interests, energies, technologies and materials assemble around a matter of concern. And most importantly for this reappraisal of representation, the public that responds to climate change is brought into being by the work of narrative gathering with a range of other forces and material things. As such, it is neither a permanent or pre-existent entity: it comes to be, according to Michael Warner, 'by virtue of being addressed' (67). Gay Hawkins' account of the POOO (People Opposed to Ocean Outfalls) protests of the late 1980s - which were a response to the high levels of human waste pollution along Sydney's 
beaches - demonstrates the ways in which a temporary public, called up by 'a vision of a contaminated world' (Hawkins 5), conditionally enables ecological citizenship, rather than impressing it as a sign. The protests saw discursive spaces of real relations and political possibilities emerge, where issues of infrastructure and social organisation assembled with the ocean, the sand, the air, and an embodied, visceral response to a smelly beach.

Thinking about ecological citizenship as produced by a contingent gathering of humans and non-humans has strong implications for the representative role of humans in an environmental democracy - that is, to speak and act on behalf of its non-human constituency. In the terms of environmental management and the commonly understood imperatives of ecological citizenship, the environment is a non-citizen that we represent. We determine the framing and limits of environmental rights: it is about what rights we extend and police. But an ecological citizenship in the expanded, materialised and more-than-representational sense indicated by the POOO protests collaboratively produces a new political vision.

The possibilities for new models of democratic participation are something that concerns natureculture research as it foregrounds new alliances between human and non-human interests and poses questions regarding how political spaces are constituted. This is also what a rethinking of representation enables. Natureculture theorists (for example, Latour, Hinchliffe, Whatmore and Hawkins) are challenging humans to form 'government' with the non-human world, and to recognise the capacity for 'co-fabrication' (Hinchliffe and Whatmore, 'Living Cities') in human/non-human alliances as a strategy for innovative political and environmental futures. If we understand reality as a co-production of human and non-human forces, then the 'knowledgeability' of nonhumans is something that the political process cannot ignore: to quote from Hinchliffe et al's work on post-representative political ecology, they become 'fellow subjects rather than performed objects' in the making of the world (Hinchliffe et al, 'Urban Wild Things' 653).

\section{Allegories}

I want to end with a final reflection on the tension that I have highlighted between how the world emerges and what we demand of representation. The hidden geographies of assembling reality cannot be captured by representation, but they can be materialised as a discursive trace, for instance in the fleeting emergence of publics that can manifest response to environmental change. Law articulates these possibilities when he insists upon the allegorical aspect of empirical work that manifests, as he explains it, as an 'alternative politics [which] softens and plays with the boundaries between what is Othered and what is made manifest' (93). Allegory, as a poetic practice, offers a particular and unsettled way of investigating the world. It gives us important glimpses of the 
multiple sites of 'out there'. As a trace, allegory points to other traces rather than to absence. It is an active agent, shaping what we know: a tool that enables us to read 'between the lines' of any apparent reality (94) in ways that acknowledge the multiplicity of presence - what is gathered together in this assemblage. Never attempting to fully capture or present a situation or relation, allegories make manifest realities '[that] do not necessarily have to fit together' (Law 90). They keep the possibility of alternate meanings always in play.

Take the ecological footprint. As a sign, the ecological footprint is an impression upon the earth. It represents a fixed boundary between human and non-human life. It is a narrow, single-voiced story of how things are, and it refuses the messy relations of scientific and poetic practice. It is non-processual and irrevocable - until, of course, we smooth out the ground erasing all traces: the only alternative provided. As a trace, however, it records a point in an ongoing entanglement; it becomes, instead, a witnessing that is part of a shifting ecology. In this sense it is an impression made in the midst of a gathering, not outside of it. What is made manifest is something partial, something on the move, and something that gathers with a multiplicity of presences.

Approached allegorically, the footprint becomes part of a pattern: it calls up the ground, the tread of the shoe, the ripple of motion, the air, and surrounding sounds - these presences made manifest forbid a single account of how things are. The belief that reality is coherent defuses the productive and uncertain potential of representation. This is the difference between viewing the world as product or process. Text doesn't just mediate the world, but is active in its making. At the same time, of course, we know the world in more than textual ways. We live materially, we run up against non-human recalcitrance, and we respond to environmental textures. The demands of environmental change expose the limits of representation but they also inspire different ways of thinking about how we come to know. Through a revised approach to representation we can keep a host of realities in tension as we seek to find meaning. This won't mean that we know climate change and its impacts in any final way. It might mean, however, that we have registered its composing complexity, and taken a stake in what it will be.

Emily Potter is a Research Fellow in the Institute for Citizenship and Globalisation, Deakin University. Her areas of research interest include creative research, cultural theory and environmental practice. She is the co-editor of Fresh Water: New Perspectives on Water in Australia (MUP, 2007), and her academic articles have appeared in both Australian and international journals including Antipodes, Media International Australia, Cultural Studies Review, and Continuum. 


\section{Works cited}

Brook, Barry. 'Science must prevail.' The Australian, 30 April 2008, 27.

Carter, Paul. The Lie of the Land. London: Faber and Faber, 1996.

Hawkins, Gay. 'Shit in Public'. Australian Humanities Review 31-2 (2004):

$<$ http://www.australianhumanitiesreview.org/archive/Issue-April-2004/ hawkins.html> Accessed 10 March 2009.

Garrard, Greg. Ecocriticism. London: Routledge, 2004.

Henson, Robert. The Rough Guide to Climate Change. London: Rough Guides, 2006.

Hinchliffe, Steve, Matthew B. Kearnes, Monica Degen and Sarah Whatmore. 'Urban Wild Things: A Cosmopolitical Experiment.' Environment and Planning D: Society and Space 23 (2005): 643-58.

Hinchliffe, Steve and Sarah Whatmore. 'Living Cities: Towards a Politics of Conviviality.' Science as Culture 15.2 (2006): 123-38.

Latour, Bruno. 'Why has Critique Run Out of Steam?: From Matters of Fact to Matters of Concern.' Critical Inquiry 30 (2004): 225-48.

-. 'From Realpolitik to Dingpolitik: or How to Make Things Public.' Making Things Public. Ed. Bruno Latour and Peter Weibel. Cambridge, MA: MIT Press, 2005.

Law, John. After Method: Mess in Social Science Research. London: Routledge, 2004.

Light, Andrew. 'Urban Ecological Citizenship.' Journal of Social Philosophy 34.1 (2003): 44-63.

McEwan, Ian. 'Let's Talk About Climate Change.' Grist Magazine, 25 April 2005. <http://www.grist.org/comments/soapbox/2005/04/25/mcewan-climate/> Accessed 10 March 2009.

McKee, Yates. 'Art and the Ends of Environmentalism: From Biosphere to the Right to Survival.' Nongovernmental Politics. Ed. Michael Feher, Gaelle Krikorian and Yates McKee. New York: Zone Books, 2007.

McKibben, Bill. 'Imagine That: What the Warming World Needs Now is Art, Sweet Art.' Grist Magazine, 21 April 2005, $<$ http://www.grist.org/comments/soapbox/2005/04/21/mckibben-imagine/> Accessed 10 March 2009.

Muecke, Stephen. Joe in the Andamans, and Other Fictocritical Stories. Sydney: Local Consumption Press, 2008. 
Potter, Emily. 'Environmental Art and the Production of Publics: Responding to Environmental Change.' International Journal for the Arts in Society 3.4 (2009): 81-6.

Sáiz, Angel Valencia. 'Globalisation, Cosmopolitanism and Ecological Citizenship.' Environmental Politics 14.2 (2005): 163-78.

Victorian Department of Sustainability and Environment. Our Water, Our Future website. <http://www.ourwater.vic.gov.au/home> Accessed 10 March 2009. 